\title{
Auto-Notify Device Bot
}

\author{
Rohan Jadhav \\ Department of Comp Engg. \\ T.S.S.M's PVPIT, Pune \\ Savitribai Phule Pune \\ University, India
}

\author{
Gaurav Tarapure \\ Department of Comp Engg. \\ T.S.S.M's PVPIT, Pune \\ Savitribai Phule Pune \\ University, India
}

\author{
Supriya Tiple \\ Department of Comp Engg. \\ T.S.S.M's PVPIT, Pune \\ Savitribai Phule Pune \\ University, India
}

\begin{abstract}
The fantastic growth of the Android Application, spectator in recent years, it has a phenomenal stroke on the way in which retailers interact and do business with their customers. The main goal of this Application is to heighten the marketing strategy. The conceptual study of this application attempt to bridge this gap by observing the length to which the acceptance of applications amongst retailers is influenced by the social ecology characteristics of their target customers.

The important concept of "Auto-Notify Device Bot" is to create a full-fledged Android application which could locate a list of nearby places based on the location in which the area of interest entered(product) by the user in his/her profile or by the manual search of product. The user has the facility to obtain the detailed review of the location he chooses from which he/she wants to buy product. The user can able to add a product and location from which user want to buy, this feature is called as Location Based Remainder.
\end{abstract}

\section{General Terms}

Admin, Customer, Seller, Location Based Remainder

\section{Keywords}

ADB (Auto-Notify Device Bot), GPS (Global Positioning System), PDA (Personal Digital Assistant).

\section{INTRODUCTION}

Modern and Smart hand held devices such as mobile phones and PDA's (Personal Digital Assistant) have become increasingly dominating in this few years. Spectacular comethroughs in processing power along with the number of special extra characteristic included in these devices have opened the avenue to a spacious scope of trading possibilities and actions. In distinct, most numerous smart phones uniformly comprise of cameras, sensors, Internet access and processors comparable to Desktop from only a few years ago. However, even with all these added capabilities, there are scarcely any applications that endure much passing of the environmental intelligence and location based utilities.

As this smart and modern devices become more like PCs they will come to replace objects we tend to carry around such as checkbooks, credit cards, cameras, planners, mp3 players, etc. In short, we will be using them to fulfil our daily tasks. One application that falls into this division is the Auto-notify Device Bot (ADB) developed for the Android Phones.

\section{RELATED WORK}

\subsection{Target (Android Application)}

The Target is a mobile application which makes shopping easier for you by giving you products to browse and search, ability to check item availability and aisle location, view the weekly ad, manage your lists and registries, and discover daily deals.

One can search shops from numerous division such as Car Showroom, Fashion/shopping, Hotels \& Lodges, Electronics \& Devices, Hospitals, Shoes \& Chapples, Gift Shops, Jewellery shops, Mobile store, Hair Saloon, Furniture, Restaurants, Banks, , GYM, Cafe, Bike Showroom.

\subsection{Buy.com (iPhone Application)}

The Buy.com is a mobile application for iPhone that assist you to discover variety of products anywhere, anytime.

Serviceable aspects for Buy.com are:

-Video reviews for products are preferred by some users.

-Can discover Top Sellers or especial deals of the week or month.

\subsection{My Nagpur (Android Application)}

My Nagpur is a shop's offer preferment application and is first of its kind peculiarly developed to suite Nagpurians needs.

- Obtain all the ATM location area wise and bank wise.

- Gives the details about service centre in Nagpur on one click example nokia care, samsung care all the product

- Gives Details of all blood bank and ambulance police station on one click on My Nagpur app.

\section{PROPOSED METHOD}

The basic idea is for an application where shop owners would be able to post information about sales, offers and discounts provided at a specific shop. By using this application, customer and user could get informed on current sales and offers without the need to go to the shop themselves. Shop owners could also use this to promote and advertise their shops. By allowing users to post such information, other people can also read comments and rate the posts (sales, offers, discounts), therefore calculating how worthy or accurate a post is and perhaps find out about the variety of items offered on sale, their availability and their price ranges.

\subsection{System Architecture}

Architecture Design gives the basic idea about of the application. It gives the information about each model in the system. It is draw to understand what we have to develop in our system. The architecture diagram must be able to understand by the every vendor of the project. Architecture diagram is draw after gathering the whole information related to the system. 


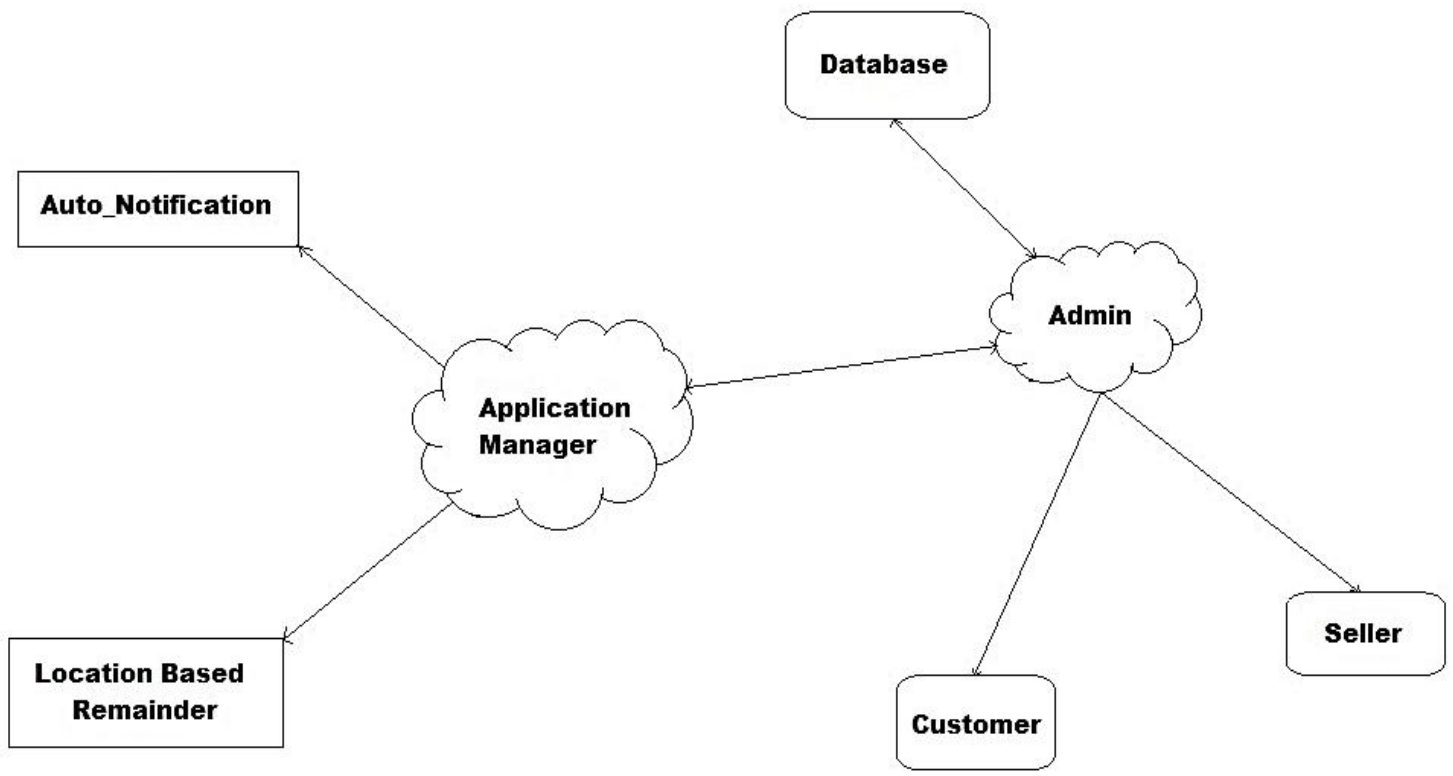

Fig 1: System Architecture

\subsubsection{Application Manager}

It manages the customer and seller model. Application manager is the heart of the system, it defines behavior and work of an each model.

\subsubsection{Location Base Remainder}

Location base remainder gives the remainder on the particular location which user sets. The customer set the remainder in the application with the location name and product name. If the customer is in that same location as he set then the remainder message pops up on mobile by the application.

\subsubsection{Admin}

Admin check the review of the system. Admin check detail of the user who is going to login. Security related all the information is check by the admin.

\subsubsection{Auto-notify}

The application gives auto notification message to the customer. According to customer area of interest, if there is any place found by the application then it give message to the customer, the detail of that place.

\subsection{Mathematical Model}

A mathematical model is a description of a system using mathematical concepts and language. The process of developing a mathematical model is termed mathematical modeling.

\subsubsection{Model of rational behavior for a user}

In this model let assume a user faces a choice of $n$ commodities labeled $\quad 1, \quad 2 \ldots n$ each with a retailer $p_{1}, p_{2} \ldots p_{n}$. The user is assumed to have a cardinal utility function $U$ (cardinal in the sense that it assigns numerical values to utilities), depending on the amounts of commodities $x_{1}, x_{2} \ldots x_{n}$ consumed. The model further assumes that the user has a budget $M$ which is used to purchase a vector $x_{1}, x_{2} \ldots x_{n}$ in such a way as to maximize $U\left(x_{1}, x_{2} \ldots x_{n}\right)$. The problem of rational behavior in this model then becomes an optimization problem, that is:

$$
U\left(x_{1}, x_{2}, \ldots, x_{n}\right)
$$

Subject to,

$$
\begin{gathered}
\sum_{\mathrm{i}=1}^{\mathrm{n}} \mathrm{p}_{\mathrm{i}}, \mathrm{x}_{\mathrm{i} \leq \mathrm{M} .} . \\
x_{i \geq 0 \forall \in\{1,2, \ldots, n\}}
\end{gathered}
$$

For Searching purpose,

$$
T(N)=T\left(\frac{N}{2}\right)+O(1)
$$

Apply Masters Theorem for Computing Run time complexity of recurrence relations,

$$
T(N)=a T\left(\frac{N}{b}\right)+f(N)
$$

Here $a=1, b=2 \Rightarrow \log ($ a base $b)=1$

Also here, $f(n)=n^{\wedge} c \log ^{\wedge} k(n)$

Where, $k=0 \& c=\log ($ a base $b)$

So,

$$
T(N)=O\left(N^{\wedge} c \log ^{\wedge}(k+1) N\right)=O(\log (N)) \text {. }
$$

\subsection{GPS Technology}

GPS Tracking is one of the most usable today's features in mobile phones used by millions of people. According to our project, users will be able to see where the stores are located and how they can get there containing meaningful directions by car or walking. Tracking services will be achieved via Google Maps because they offer several and helpful information about the location of places. Specifically, every offer is associated with its store so user will be able to get directions using the GPS tracking operation thus finding directions on how to visit the shop from a specified location. Additionally, when the user watches a particular offer or discount then all nearby shops will be appeared on the screen allowing user to visit these ones as well especially when he/she is at that region.

\subsection{Case Studies}

One of the main and important outline of the ADB application is to let the users post new offers and discounts and share it with other users. A distinct scenario is when a shop owner decides to post the offers and discounts related to his shop 
with profit perspective. He can use the application similarly and post the information and share it with other users (Here the post will be mostly public).

\section{Differentiation of users to shop owners and simple users:}

The users of the application are divided into two categories: normal users as well as customers and shop owners. Normal users or customers are regular application users who use the application for viewing and sharing offers and discounts from third party sources. In opposite to normal users, shop owner user category is first-hand information source whose members can use the application to input the offers and discounts available at their stores in the wise generating new content and can share it with other users. Thus the application provides a platform which the shop owners can purchase to profit their business.

\section{Users are able to rate offers:}

Every user will be able to rate the offers shown in our application. The unite rating from all offers of a user will be his/her rating, so other users will know if he/she is a good/reliable one in order to trust him/her. The ratings will be out of 5. This rating will show if an offer can be trusted or if it is a good deal for other users.

\section{Shop Rating and Subscription:}

Another feature of our application would be a subscription to a shop you like and also find out the best shops with the best rating. Each shop in the application it will be considered as a different item but also as a producer of the offers that are announced for them. As a result, each user can subscribe on a shop and the application will inform him about new offers by the way of email or by forecasting the newly offers about shops that was subscribed on the home page.

\section{CONCLUSION}

We have noticed the execution of auto-notify device bot. It useful not only in discovering the location of shops but also it is helpful in saving the time of buyers as well as of sellers. It can be used to reduce the time need to shop and due to the location based remainder and auto-notification it serve to customer as a personal help in less amount of ratio. Finally we can say that the project has many superior advantages and hence it can be beneficial in day to day life.

\section{FUTURE SCOPE}

1) Voice search. Could help users use application while driving or doing something else at the same time.

2) Can compare prices from this application and thousands of other merchants while shopping in local stores.

\section{ACKNOWLEDGEMENT}

Our thanks to the experts who have bestow towards development of the paper.We would also like to thank the viewers for their intimation to improve this paper.

\section{REFERENCES}

[1] Location based services on Android http://blogs.itemis.de/frey/2009/04/04/location-basedservices-on-android-part-1/
[2] Code snippets for Android development http://stackoverflow.com/

[3] Android Development Guide http://developer.android.com

[4] Create Icon with Text Using Grid View and Layout Inflater

http://oudomvilla.wordpress.com/2010/08/23/create-iconwith-text-using-gridview-and-layout-inflater/

[5] Icons used in the project (used only for project purpose). http://www.fasticon.com/

[6] Google Projects for Android: Google APIs http://code.google.com/android/add-ons/googleapis/maps-overview.html

[7] Parsing XML using SAX Parser http://www.anddev.org/novice-tutorials-f8/parsing-xmlfrom-the-net-using-the-saxparser- $\mathrm{t} 353 . \mathrm{html}$

[8] Android development system requirements http://developer.android.com/sdk/requirements.html

[9] Android Architecture from Android developer site http://developer.android.com/guide/basics/what-isandroid.html

[10] Android architecture from Wikipedia http://en.wikipedia.org/wiki/Android_(operating_system)

[11] Android architecture from How Stuff Works http://electronics.howstuffworks.com/google-phone2.html

[12] Use Case Diagram http://en.wikipedia.org/wiki/Use_case_diagram

[13] Unified Modeling Language http://en.wikipedia.org/wiki/Unified_Modeling_Language

[14] Connection between PHP (server) and Android (client) Using HTTP and JSON Connection http://fahmirahman.wordpress.com/2011/04/21/connectio n-between-php-server-and-android-client-using-http-andjson/

[15] Create Icon with Text Using Grid View and Layout Inflater

http://oudomvilla.wordpress.com/2010/08/23/create-iconwith-text-using-gridview-and-layout-inflater/

[16] Itemized Overlay http://code.google.com/android/addons/google-

apis/reference/com/google/android/maps/ItemizedOverlay .html

[17] Class http://en.wikipedia.org/wiki/Class_diagram

Diagram

[18] Performance and Cost of GSM/GPRS/EDGE Solutions http://www.lysko.com/fromPSTNtoWCDMA.htm

[19] Software

Testing http://en.wikipedia.org/wiki/Software_testing

[20] DDMS

http://developer.android.com/guide/developing/debugging /ddms.html 